\title{
İntestinal Stomanın Gebelik Sürecine Etkisi ve Hemşirelik Bakımı
}

The Effect of Intestinal Stoma on Pregnancy Process and Nursing Care

\author{
Hatice Merve ALPTEKIN ${ }^{1}$, Eda ŞIMŞEK ŞAHIN ${ }^{2}$
}

\section{Öz}

Stoma, hastanın hayatını kurtarmak, yaşam kalitesini arttırmak için sıklıkla uygulanan cerrahi girişimlerden biridir. Stomalı hastaların gebe kalamayacağı gebe kalsa bile gebeliği sağlıklı bir şekilde sürdüremeyeceği ya da vajinal doğum yapamayacağı ile ilgili, yanlış bir inanış vardır. Stoması olan kadınlar tekil ya da çoğul gebelik yaşayabilir, gebenin ve fetüsün durumuna göre vajinal ya da sezeryan doğum eylemini başarılı şekilde gerçekleştirebilir. Fakat gebelik haftasının ilerlemesiyle birlikte stoma boyutundaki değişimler ve abdomenin konveks bir hal alması sonucu stoma torbasını değiştirmede sorun yaşanabilir. $\mathrm{Bu}$ nedenle stoması olan kadınların gebelik boyunca stoma boyutları ve stomaya ilişkin komplikasyonlar açısından değerlendirilmeleri gerekmektedir. Ayrıca kadınlara hem gebeliğinde hem de stomasında yaşayabileceği değişimler ile ilgili stoma bakım hemşiresi tarafından eğitim verilmesi gerekmektedir. Üreme çağındaki stomalı kadınların gebe kalıp kalamayacakları, gebe kaldıklarında bu süreci nasıl geçirecekleri ve sağlık profesyonellerinin bu konudaki deneyimleri ile ilgili literatürde sınırlı sayıda çalışma mevcuttur. $\mathrm{Bu}$ araştırmanın amacı intestinal stoması olan üreme çağındaki kadınların gebelik süreci ve hemşirelik bakımı ile ilgili bilgi sağlamaktır.

Anahtar Kelimeler: Hemşirelik, Bakım, Stoma, Gebelik

\begin{abstract}
Stoma is a surgical intervention that is frequently applied to save the patient's life and improve the quality of life. There is a misconception that patients with stoma cannot become pregnant, even if they do, they cannot reach term or have vaginal delivery. Women with stoma may experience singleton or multiple pregnancies and may perform vaginal or caesarean section according to the condition of the pregnant and fetus. However, changes in stoma size and the convexity of the abdomen may cause problems in changing the stoma bag as the pregnancy approaches to term. Therefore, women with stoma should be evaluated in terms of stoma sizes and complications related to stoma during pregnancy. In addition, women should be trained by the stoma care nurse about the changes they may experience in both pregnancy and stoma. There are limited studies in the literature regarding whether women with stoma can become pregnant in the reproductive period, how to go through this process when they become pregnant, and the experiences of health professionals in this area. The aim of this study is to provide information about the pregnancy process and nursing care of women of reproductive age with intestinal stoma.
\end{abstract}

Keywords: Nursing, Care, Stoma, Pregnancy

\footnotetext{
* 2.Uluslararası Kadın Çocuk Sağlı̆̆ı ve Eğitimi Kongresi’nde sözel bildiri olarak sunulmuş ve geniş özet olarak kongre kitabında yayınlanmıştır.

${ }^{1}$ Arş. Gör. Cerrahi Hastalıkları Hemşireliği, İstanbul Üniversitesi-Cerrahpaşa Lisansüstü Eğitim Enstitüsü Florence Nightingale Hemşirelik Fakültesi, Hemşirelik Bölümü, imervealptekini@hotmail.com, ORCID: 0000-0002-4544-7987

${ }^{2}$ Arş. Gör. Doğum ve Kadın Hastalıkları Hemșireliği, Gazi Üniversitesi Sağlık Bilimleri Fakültesi, Hemșirelik Bölümü, simsekeda24@gmail.com, ORCID: 0000-0002-1614-9569
} 
Stoma, Latince'de ağızlaştırma anlamına gelen, vücut atıklarının normal fizyolojik açıklıktan farklı olarak uzaklaştırılmasını sağlamak üzere yapılan cerrahi bir girişimdir. Stomalar bulundukları bölgelere göre; incebağırsakta açılan stomalar ileostomi, kalınbağırsakta açılan stomalar kolostomi olarak adlandırılmaktadır. ${ }^{1,2}$ Amerika Birleşik Devletleri'nde her yıl 100.000'in üzerinde stoma cerrahisi uygulanmaktadır. ${ }^{2}$ Toplam stoma açılmış birey sayısının ise 725.000 ile 1 milyon arasında olduğu düşünülmektedir. ${ }^{3}$ Ülkemizde 2017 yılında yayınlanan Kamu Hastaneleri istatistik yıllığgna göre 2017 yılı içeresinde toplam 2.509 kişiye kolostomi açıldığ1 bilinmektedir. ${ }^{4}$ İntestinal stoma cerrahisi kolon kanseri, crohn, travma, divertikülit, konjenital anomali, enflamatuar barsak hastalığı sebebiyle uygulanabilmektedir. ${ }^{5}$ Stomalar hastalığın gelişimine bağlı olarak geçici veya kalıcı olabilmektedir. Stomalar ister gebelik döneminde olsun isterse gebelik diş1 dönemlerde olsun kadın sağlığını olumsuz etkilemektedir. ${ }^{2,6}$

\section{Stomanın Cinsellik Üzerine Etkisi}

Stomas1 olan bireylerde siklikla beden imajının bozulması ve benlik saygısında azalma olmasinın yanı sira stomadan kaynaklı gaz ve koku problemi, cinsel ilişki sırasında stoma torbasının çıkacak olması korkusu bireylerin cinsel ilişkiden kaçınmalarına ve cinsellikle ilgili problemler yaşamalarına neden olmaktadır. , $^{27,8}$ Stomanın varlığı eşler arasında da sorun oluşturabilmekte bireylerin “. .. yaklaşık 4 aydır cinsel ilişkiye giremiyoruz ve kocam bu konuda çok şikayetçi."7 “...ameliyattan sonra kocamla olan ilişkimden endişelendim. İlk başta utaniyordum, ancak dernekte benzer koşulları olan diğer kadınlarla iletişim kurup eşimle danışmanlık oturumlarına katıldıktan sonra endișem azaldı" söylemleri de bunu desteklemektedir. ${ }^{7,9}$ Fizyolojik faktörlerin yanı sira stomalı bireylerin cinsel sorunlarının altında psikolojik ve duygusal

\section{GİRIS}

faktörlerin de rol oynadığı, "stomam olduğu için beni kimse sevmez, stomanın sebep olduğu koku nedeniyle partnerim benden uzaklaşır, stoması olan kadınlar hamile kalamaz, cinsel aktivite stomaya zarar verir..." gibi mitlerin de bireyleri olumsuz yönde etkilediği düşünülmektedir. ${ }^{10,11}$ Anaraki ve ark. ${ }^{12}$ yaptığı çalışmada stomalı bireylerin \%70'nin cinsel aktivitelerinden memnun olmadiğını bildirmiştir. Weerakoon ${ }^{13}$ yaptığı çalışmada stomalı bireylerin \% 78 'inde cinsel fonksiyonlarında azalma, \%34'ünde cinsel doyum oranlarında azalma olduğunu belirlemiştir. Silva ve ark. ${ }^{14}$ yaptıkları çalışmada ise ileostomili hastaların \%95'inin, kolostomili hastaların ise \%81'inin cinsel sorunlar yaşadıklarını tespit etmişlerdir. Ayaz ve Kubilay' $1 n^{15}$ yaptıkları çalışmada stoması olan hastalara PLISST modeli (permission, limited information, special suggestions, intensive therapy) ile bakım verilmiş ve bakımın cinsel fonksiyonlarda düzelme sağladığı, bakım almayan grubun cinsel fonksiyonlarının bozulduğu, deney grubundaki katılımciların cinsel doyuma ilişkin sorunları ve cinsel aktivite sıklığına ilişkin problemleri daha az yaşadığı belirlemişlerdir. ${ }^{15}$

Cinsel yaşamdaki sorunlar bireylerin yaşam kalitesini, sosyal aktivitelerini, kişisel ilişkilerini, stomaya uyumlarını ve tedaviye katılımlarını etkilemesi bakımından da büyük önem arz etmektedir. ${ }^{2,16} \mathrm{Bu}$ nedenle stoma varlığının cinsel aktiviteye engel olmadığ1 konusunda bireylerin bilgilendirilmesi, stomalı kadınlarda görülebilecek problemler (cinsel istekte azalma, disparoni, orgazm bozuklukları, vajinal kuruluk ve nadiren infertilite) hakkında danışmanlık verilmesi ya da danışmanlık alabileceği yerler ile iletişime geçmesi sağlanmalı, destekleyici bir ortam oluşturulmalıdır. 9,10,11,17,18

\section{Stomanın Gebelik, Doğum Şekli ve Doğum Sonrası Sürece Etkisi}

Stoma ameliyatı geçiren kadınlarda nadiren infertilite gelişmekle birlikte, ${ }^{11}$ 
sadece stomaya sahip olmak infertilite için geçerli bir neden değildir. ${ }^{11,19}$ Ayrıca infertilite kompleks nedenli de olabilmektedir. Stomanın açılmasına yol açan spesifik hastalık, hastanın kendisinin ya da partnerinin fertilitesini etkileyebilmektedir. Fertiliteyi fiziksel nedenlerin yanı sıra stomanın varlığına bağlı psikolojik faktörlerin de olumsuz etkilediği bilinmektedir. ${ }^{10}$ Stomanın varlığı fiziksel olarak gebe kalmaya engel olmamasina rağmen $^{19}$ stomalı kadınlar; gebe kalıp kalamayacakları, gebe kalsalar bile bu gebeliği sağlıklı şekilde devam ettirip ettirmeyecekleri ve vajinal doğum yapıp yapamayacakları konusunda endişe duymaktadır. $\mathrm{Bu}$ tarz endişelerin varlığına rağmen tekil veya çoğul gebeliklerin oluştuğu rapor edilmiştir. ${ }^{10,20} 1950$ 'li yıllardan beri birçok çalışma stoması olan kadınlarda gebeliklerin oluştuğu ve doğum eyleminin gerçekleştiğini kaydetmiştir. ${ }^{10}$

Stoması olan kadınların her ne kadar gebe kalıp sağlıklı bir şekilde bebek dünyaya getirebileceği ifade edilse de gebelik planlanmadan önce, gebelik sirasında ve sonrasında mutlaka multidisipliner sağlik ekibi gözetiminde yakından takip edilmesi, kaygılarının eğitimler ve danışmanlıkla giderilmesi, kadının yaşayabileceği olası durumlar için hazırlıklı hale getirilmesi önem taşımaktadır. ${ }^{11,19}$ Üreme çağında olup da stoması bulunan kadınların plansız bir gebelik yaşaması hem kadının kendi sağlık durumu hem de fetüs için ek sorunlara yol açacağı için dikkatle ele alınması gereken bir konudur. ${ }^{1} \mathrm{Bu}$ doğrultuda gebelik önleyici yöntemlerin stoma cerrahisi öncesinde ve sonrasında eğitimi verilmeli, kadınlara bu konuda destek olunmalıdır. Gebelik önleyici yöntem olarak oral kontraseptifleri tercih eden bir kadına bu hapların ince bağırsakta emildiği, stomaya bağlı emilimde azalmalar olabileceği bu nedenle gebelik riskinin oluşabileceği bilgisi mutlaka verilmelidir. Yöntem olarak diyafram ya da rahim içi cihazları tercih eden kadınların rektum ya da vajinal duvara müdahale edilmediğinden emin olunmalıdır. Hormonlu cilt yamaları, aylık ve üç aylık enjeksiyonlar gibi diğer yöntemler hakkında da kadına bilgi verilerek seçim şansı sağlanmalıdır. ${ }^{11}$

Stoması olan gebelere ilişkin literatür incelendiğinde; stomalı kadınların \%25'inin gebelikte stoma torbası ile ilgili problem yaşadığı, bu problemlere siklıkla 2 . ve 3 . trimesterde stomanın boyutlarındaki değişikliklerin yol açtığ 1 bildirilmiştir. Bunun en önemli nedeni gebelik haftas1 ilerledikçe abdomenin konveks bir hal alması ve gebenin stoma görüşünün azalmasıdır. $\mathrm{Bu}$ sorunla baş etmek için sıklıkla ayna kullanılarak stoma torbasının değişimi ve izlemi yapılması önerilmektedir. ${ }^{10}$ Stomalı gebelerde uterusun genişlemesi ile birlikte stomanın yerinde değişim olabileceği ve s1k kontrollere gidilmesi gerektiği konusunda uyarıda bulunulmalıdır.

Gebelikle birlikte artan progestron salınımı, abdominal basınç ve büyüyen uterus ile fetüsün mekanik basıncı bağırsak peristaltizmini azaltır. Bu nedenle gebelerde boşaltım ile ilgili problemler çok daha fazla görülür. ${ }^{21,22,23,24}$ Stomalı gebelerin $\% 15$ 'nde bağırsak obstrüksiyonu görülmektedir. $\mathrm{Bu}$ problemle karşılaşmamak için gebenin 3. trimestere girdiğinde doktorunun kontrolünde diyet kısıtlaması yapabileceği ya da medikal destek alabileceği bu şekilde abdominal rahatsızlığı ve sabah bulantılarını azaltabileceği bildirilmiştir. $^{10}$ Ayrıca gebelerin sıv1 ve lifli gıda alımını artırmaları, fiziksel olarak aktif olmaları gastrointestinal sistem rahatsızlıklarının azaltılmasına yardımcı olmaktadır. ${ }^{21,22,23,24}$

Stoması olan gebelerin $\% 85$ 'inde, gebelik sürecinde stomayla ilgili herhangi bir komplikasyon yaşanmadığ durumun doğum eylemi üzerinde herhangi bir etkisi olmadığı bildirilmiştir. ${ }^{25}$ Buna rağmen gebelikte bazı komplikasyonlar görülmektedir. En yaygın olanları; stomanın yer değiștirmesi, genişlemesi, prolapsusu, intestinal obstruksiyon, stoma torbas1 sorunları, darlık, kanama, laserasyon, üriner enfeksiyon ve elektrolit dengesizliğidir. $25,26,27$

Stomalı gebelerin yaşadıkları komplikasyonların değerlendirildiği 
sonuçlandığını, 7 gebelikten sadece 1

çalışmalarda; gebelerin \%10'nunda 3 . trimester sirasinda stomal prolapsus gerçekleştiği, stomal prolapsus gelişen gebelerin $\% 75$ 'inde ise cerrahi girişim gerekmediği doğum eylemi ile sorunun giderildiği, gebelerin \%3'de gebelikle birlikte abdomen duvarındaki esneme ve karın içi basıncın artmasına bağlı peristomal herni görüldüğü, doğum sonrası peristomal herni yaşayan kadınların yarısının cerrahi tamire ihtiyaç duymaksızın hernilerinin düzeldiği yarısının ise postpartum dönemde cerrahi tamire ihtiyaç duydukları bildirilmiştir. ${ }^{10,28}$

Ayrıca gebelik sırasında stomanın diğer komplikasyonları; kanama, aplikatörü uygularken stoma girişini genişletme, stomanın retraksiyonu ve enfeksiyondur. ${ }^{10}$ Enfeksiyonu önlemek için antibiyotik kullanımı önerilmektedir. ${ }^{10}$ Ancak gebelikte ilaç kullanımı hem anne hem de bebek sağlığııı yakından ilgilendiren bir durum olup ilaçların yalnızca \%10'nun gebelikte kullanımının güvenli ve etkili olduğuna ilișkin bilgi mevcuttur. Günümüzde birçok ilacın teratojenik etkisi de henüz bilinmemektedir. Ayrıca gebelikte meydana gelen fizyolojik değişimler ilaçların farmakokinetik özelliklerini etkileyebilmektedir. $\mathrm{Bu}$ nedenle gebelikte antibiyotik kullanımı dikkatle irdelenmesi gereken bir konudur. ${ }^{29,30}$ Ayrica oral antibiyotikler ishale yol açabileceği için stomalı hastalarda ilaç kullanımında hassas olunmalidır. ${ }^{1}$

Hassas olunması gereken bir diğer konu da doğum yöntemine karar verilirken tüm gebelerde olduğu gibi stomalı gebelerde de obstetrik ve fetal ihtiyaçların göz önünde bulundurulmasıdır. ${ }^{27}$ Çünkü stomalı kadınlar da vajinal ya da sezaryen doğum yapabilirler. ${ }^{10,28}$ Sezaryen doğum kararının verilmesinde rektal yara izi, sfinkter yetmezliği veya rektovajinal fissür öyküsü önemli bir belirleyicidir. Doğum eyleminde sıklıkla (\%94) indüksiyona ihtiyaç duyulmamaktadır. ${ }^{10}$ Takahashi ve ark. ${ }^{20}$ stomalı gebeler ile ilgili yaptıkları araştırmada 7 gebeliğin 6'sının sezaryen doğum 1 tanesinin ise vajinal doğum ile tanesinin erken doğum ile gerçekleştiğini bildirilmiştir. $^{20}$

Stomalı kadınların gebelikleri ve gebelik boyunca karşılaşabilecekleri olası problemler fetüsün büyüme ve gelişmesi, yenidoğanın sağlıklı olup olmayacağ konusunda soru işaretlerini akla getirmektedir. Literatürde konu ile ilgili çalışma sayısının yetersiz olmasına karşın intrauterin ortamda fetüsün büyümesinin ultrasonografi ile değerlendirildiği çalışmada fetüslerin femur boyu biparyetal diamater uzunluğunun gebelik haftası ile uyumlu olduğu bildirilmiştir. ${ }^{20}$ Takahashi ve ark. $^{20}$ çalışmasında infantlardan birinin düşük doğum ağırlıklı olarak doğduğu, vakalardan birinde yenidoğan asfiksinin geliştiği, asfiksi gelişen yenidoğanın 5 . dakika APGAR (cilt rengi, kalp hız1, refleksler, kas tonusu ve solunum) skorunun 8'e yükseldiği ve yenidoğanın genel durumunun iyileşti bildirilmiştir. ${ }^{20}$

Yenidoğanın yanı sıra doğum sonu dönemde anneye ilişkin kaygılar da mevcuttur. Doğum sonu dönem kadının hem vücudundaki değişimlere hem de bebeğine uyumunun olduğu yakından takip edilmesi gereken bir dönemdir. Stomalı kadınların rutin doğum sonu değerlendirmelerinin yanı sıra stomaya ilişkin komplikasyonlar açısından da değerlendirilmesi gerekmektedir. Doğum sonu dönemde sıklıkla komplikasyon olmamasına karşın nadiren kalicı peristomal herni, stoma torbasına ilișkin zorluklar ve stoma bölgesinde ağrı görülebilmektedir. ${ }^{10}$

Doğum sonu dönemde kadının genel durumu ve stomaya ilişkin komplikasyonların takip edilmesi ve önlenmesine ek olarak yenidoğanın olabildiğince kısa sürede emzirilmesi ve emzirmenin devamlılığ 1 da önem taşımaktadır. Emzirmenin etkili olabilmesi için annenin konforunun sağlanması ve emzirme esnasinda stomadan gelebilecek sızıntıların önlenmesi için stoma torbasının değiştirilmesi/boșaltılması olacaktır. ${ }^{10}$ 
Stomalı bireyler hem ameliyat öncesinde (bağırsak temizliği, beslenme vb.) hem de ameliyat sonrası dönemde (stoma torbasının değiştirilmesi, gebelik ve doğum vb.) birçok konuda danışmanlığa ihtiyaç duymaktadır. $\mathrm{Bu}$ nedenle hemşireler stoma açılacak bireyleri kapsaml bir şekilde değerlendirmeli ve belirlenen konular hakkında hemşirelik bakımı vermelidir.

\section{Stoma Ameliyatı Öncesi ve Sonrası Hemşirelik Girişimleri}

\section{Ameliyat Öncesi Dönemde}

Ameliyat öncesi dönem ameliyat sonrasında görülebilecek komplikasyonları azaltmak amacıyla hastaları bilgilendirildiği çok önemli bir dönemdir. $\mathrm{Bu}$ dönemde hastalar hem fiziksel hem de psikolojik olarak ameliyata hazırlanmalıdır. ${ }^{31,32}$

- İstemi yapılan ilaç tedavileri uygulanmalıdır (sedatifler, profilaktik antibiyotik vb.). ${ }^{1,32}$

- Hastalar küçük porsiyonlar ile sik aralıklarla beslenmelidir. Ayrıca yeterli beslenmenin sürdürülebilmesi için ameliyattan birkaç gün önce protein ve karbonhidrattan zengin gidalarla beslenmesi önerilmelidir. ${ }^{1,32}$ Eğer hasta ameliyat günü hastaneye yatmışsa, parenteral yol ile mineral ve vitamin eksiği tamamlanmalıdır. ${ }^{1}$

- Ameliyattan 6-8 saat önce katı gidaların yenmesi, 4 saat önce süt, ayran vb. içilmesi ve 2 saat önce berrak sıvıların tüketilmesi engellenmelidir. ${ }^{33}$

- Ameliyattan önceki akşam veya ameliyat sabahı mekanik bağırsak temizliği yapılmalıdır. ${ }^{1,32}$

- Hastanin sivi dengesinin sürdürülebilmesi için aldığı çıkardığ 1 takibi yapılmalı ayrıca serum elektrolit düzeyleri, cilt turgoru ve muköz membran değerlendirilmeli, hastada oluşabilecek hipovolemi, hipokalemi, hiponatremi bulguları yönünden hasta gözlenmelidir. ${ }^{1,33}$

- Hastalara yapılan bilgilendirmede yazılı ve resimli eğitim materyalleri kullanılmalı ve uygulamalı eğitim verilmelidir. Bu eğitim stoma drenajının yönetimi, nazogastrik tüp gerekliliğini, parenteral siv1 uygulamalarını içermelidir. ${ }^{1,33}$

- Ameliyat öncesi hasta eğitimde stoma bakımı, diyet kısıtlaması, ağrı kontrolü, solunum egzersizlerini içermelidir. ${ }^{32,33}$

- Ameliyat öncesi hazırlıkta en önemli aşamalardan biri stoma yerinin belirlenmesidir. Stoma açılacak bölge stoma hemşiresi ve cerrah tarafindan işaretlenmelidir. Stoma açılacak bölgede skar, kemik çıkıntısı ve katlanan bir bölge olmamasina özen gösterilmelidir. Ayrıca stoma bölgesi seçilirken hastaların gebe kalma ihtimali de göz önünde bulundurulmalıdır. Gerekirse göbek üzerinden stoma açılabilmektedir. ${ }^{1,31,32}$

- Hastaların ameliyata ilişkin korkuları veya öfkeleri olabilir. $\mathrm{Bu}$ aşamada hastalar bilgilendirilmeli ve duygusal olarak desteklenmelidir. Konuşmak, ağlamak, soru sormak isteyen hastalara zaman ayrilmali, tedavi ve prognozu hakkında görüşmek istiyorsa görüşmesi sağlanmalıdır. Ayrica stoma yönetiminde başarılı olmuş benzer bir hasta ile görüştürülebilir. ${ }^{1,2}$

- Hastaların gebe kalmak, doğum, cinsellik ile ilgili endişelerini ifade edebilmeleri için firsat verilmeli ve bu endişeler giderilmelidir. ${ }^{1,2}$

\section{Ameliyat Sonrası Dönemde}

- Stomanın rengi, ölçüleri ve fekal içerik değerlendirilmelidir. ${ }^{1}$

- Başlangiçta stomanın ödemli olduğu daha sonra çapının değişeceği hastaya açıklanmalıdır. Ayrıca gebelik sebebiyle stomanın yerinde değişim olabileceği, hastaların bakımlarını ayna yardımı ile yapmaları gerektiği konusunda bilgilendirilmelidir. ${ }^{1}$

- Stoma torbasının değiştirilmesi, torbanın kalma süresi ve torba çeşitleri hastaya anlatılmalıdır. ${ }^{1,19}$

- Stoma cerrahi girişimi deneyimleyen kadınların gebeliğgi doğru zamanda planlayabilmeleri için stoma tarafindan 
etkilenmeyecek gebelik önleyici yöntemler konusunda kadınlar ve partnerleri bilgilendirilmelidir. ${ }^{1,11}$

- Hastalar ameliyat sonrasi erken dönemde sıvı kaybettikleri için aldığı, çıkardığı sıvı izlemi dikkatli yapılmalıdır. ${ }^{1}$

- Hastalarda nazogastrik aspirasyonu sağlamak amaciyla nazogastrik tüp kullanılabilir. Nazogastrik tüp varsa, çekildikten sonra sıvı besinleri içmesine izin verilir daha sonra yarı katı ve katı besinlere geçilir. Bulantı ve kusma obstrüksiyon belirtisi olduğundan hastalar gözlenmelidir. Ayrıca hastaların beslenmelerine dikkat etmeleri gerektiği, diyare ve konstipasyonun görülebileceği anlatılmalıdır. ${ }^{1,19}$

- Hastaların gaz ve kokuya neden olacak yiyecekleri (yumurta, peynir, balık, kurufasulye, nohut, lahana, soğan, sarımsak, asitli içecekler vb.) Kontrollü tüketmesi gerektiği açıklanmalıdır. ${ }^{1,19}$

- Stoma cerrahi girişimi deneyimleyen kadınların gebeliği doğru zamanda planlayabilmeleri için stoma tarafindan etkilenmeyecek gebelik önleyici yöntemler anlatılmalı ve hastalar bilgilendirilmelidir. ${ }^{1,11}$

- Gebelikte tüm sistemlerde değişiklikler gözlenmektedir bu durum dolaylı yoldan stomayı etkilemekte ve stoma ile ilgili ek problemlere yol açmaktadır. Bunlar; stoma torbası ile ilgili problemler, stoma komplikasyonları ve ek olarak stoma açılmasına sebep olan hastalığın alevlenmesi veya hastalığın medikal tedavisine sekonder ortaya çıkan problemler de yaşanabilmektedir. $\mathrm{Bu}$ nedenle öncesinde gebeler bu konularda bilgilendirilmelidir. ${ }^{1,27,31}$

- Gebelerde ilaç kullanımının sınırlı olması dolayısı ile stoma açıldıktan sonra kontrendikasyonlar yönünden gözlenmeli hastanın kullandığı ilaçlar ve bitkisel ürünler kontrol edilmelidir. ${ }^{1,29,30}$

- Ameliyat sonrasi dönemde hastaların yaşam kalitesini arttırmak için malzemeleri nasıl temin edeceği, sorun yaşadığında ulaşabileceği kişilerin numarası ve gebe kalmak isteyen hastalar için stomanın gebeliğe etkileri ile ilgili konularda eğitim verilmelidir. ${ }^{1,34,35}$

\section{SONUÇ VE ÖNERÍLER}

Stoma açılan kadınların üreme çağında olması beraberinde gebelik isteğini ya da plansız gebelik problemini getirmektedir. $\mathrm{Bu}$ durum gebeliği önleyici yöntem danışmalığ ve gebelik öncesi bakımı her kadında olduğu gibi stoması olan kadınlar için de önemli hale getirmektedir. Stoması olan kadınlar tekil ya da çoğul gebelik yaşayabilir, gebenin ve fetüsün durumuna göre vajinal ya da sezeryan doğum eylemini başarılı şekilde gerçekleştirebilir. Fakat stoması olan kadınların gebelik boyunca stoma boyutları, stoma torbasi ile ilgili problemler ve stoma komplikasyonları açısından mutlaka değerlendirilmeleri gerekmektedir. Kadınların hem gebeliğe hem de stomasında yaşayabileceği değişimlere karşı hemşire tarafindan eğitimlerle hazırlanması, stoma bakımı ve gebeliğin sağlıklı sürdürülebilmesi için büyük önem taşımaktadır.

KAYNAKLAR

1. Aksoy G, Çavdar İ. (2015). Yara ve Stoma Bakımı, Sindirim Sistemi Stomalarında Bakım Edt. Akyolcu N, Kanan N, Nobel Tip Kitapevi, ss:62-85.

2. Tuna PT, Uslu E, Kurşun Ş. (2017). İntestinal Stomanın Cinsel Yaşam Üzerine Etkisi: Sistematik Derleme, Gümüşhane Üniversitesi Sağlık Bilimleri Dergisi, 6 (2), 113-121.

3. Living with an Ostomy: FAQS, https://www.ostomy.org/livingwith-an-ostomy/ Erişim Tarihi: 09.08.2019.
4. Sağlık Bakanlığı Türkiye Kamu Hastaneleri Kurumu (T.C.). Kamu hastaneleri istatistik yıllığı $2017 . \quad$ Ankara; 2018.https://dosyasb.saglik.gov.tr/Eklenti/31096,turkcesiydijiv1pd f.pdf?0.Erişim Tarihi: 13.08.2019.

5. Mitchell KA, Rawl SM, Schmidt CM et al. (2007). Demographic, Clinical and Quality of Life Variables Related to Embarrassment in Veterans Living with an Intestinal Stoma, J Wound Ostomy Continence Nurs. 34 (5), 524-532. 
6. Kılıç E, Taycan O, Belli AK ve ark. (2007). Kalıcı Ostomi Ameliyaanın Beden Algısı, Benlik Saygısı, Eş Uyumu ve Cinsel İşlevler Üzerine Etkisi, Türk Psikiyatri Dergisi, 18 (4),302-310.

7. Ceylan H, Vural F. (2017). Living with stoma-A phenomenological study. J Nurs Res Pract, 1 (1), 6-12.

8. Vonk-Klaassen SM, de Vocht HM, den Ouden ME. M, Eddes, EH, Schuurmans MJ. (2016). Ostomy-related problems and their impact on quality of life of colorectal cancer ostomates: a systematic review. Quality of Life Research, 25 (1), 125-133.

9. Dabirian A, Yaghmaei F, Rassouli, M, Tafreshi MZ. (2010). Quality of life in ostomy patients: A qualitative study. Patient Preference and Adherence, 5, 1-5.

10. Robb BW, Raffertty JF. (2003.) Pregnancy an The Ostamate, Proquest Central, 40, 3, 60.

11. Intimacy after ostomy surgery guide. United Ostomy Associations of America, Inc. https://www.ostomy.org/wpcontent/uploads/2018/03/IntimacyAfter-Ostomy-Surgery-Guide.pdf. Erişim Tarihi: 17.04.2020

12. Anaraki, F., Vafaie, M., Behboo, R., Maghsoodi, N., Esmaeil- pour, S., \& Safaee, A. (2012). Quality of life outcomes in patients living with stoma. Indian Journal of Palliative Care, 18 (3), 176.

13. Weerakoon P. (2001). Sexuality and The Patient with a Stoma. Sexuality And Disability, 19 (2),121-129.

14. Silva MA, Ratnayake G, Deen KI. (2003). Quality of Life Stoma Patients: Temporary Ileostomy Versusu Colostomy. World Journal Of Surgery, 27 (4),421-424.

15. Ayaz S, Kubilay G. (2008). Effectiveness of The Plissit Model for Solving The Sexual Problems of Patients with Stoma. Journalof Clinical Nursing, 18 (1),89-98.

16. Gözüyeşil E, Taylan S, Inel Manav A, Akil Y. (2017) The Evaluation of Self-Esteem and Sexual Satisfaction of Patients with Bowel Stoma in Turkey Sex Disabi 35, 157-169.

17. New Ostomy Patient Guide. United Ostomy Associations of America,Inc.https://www.ostomy.org/wpcontent/uploads/2018/05/ All-In-One-New-Patient Guide_2018.pdf. Erişim Tarihi: 17.04.2020

18. Junkin, Joan; Beitz, Janice M. Sexuality and the Person With a Stoma: Implications for Comprehensive. (2005). WOC Nursing Practice, Journal of Wound, Ostomy and Continence Nursing: 32 (2), ss. 121-128.

19. Ileostomy Guide. United Ostomy Associations of America, Inc. https://www.ostomy.org/wpcontent/uploads/2018/03/IleostomyGui de.pdf. Erişim Tarihi: 17.04.2020

20. Takahashi K, Funayama Y, Fukushima K, Shibata C, Ogawa H, Kumagai E, Sasaki I. (2007). Pregnancy and Delivery in Patients with Enterostomy due to Anorectal Complications from Crohn's Disease, Int J Colorectal Dis, 22, 313-318.
21. Taşkın L. (2019). Doğum ve Kadın Sağlığı Hemșireliği. Akademisyen Kitabevi.ss.69-107.

22. Gümüşsoy S, Kavlak O. (2016). Gebelikte Fizyolojik Değişiklikler. İçinde: Sevil Ü, Ertem G. Perinatoloji ve Bakım. Ankara Nobel Tıp Kitapevi. ss.101-126.

23. Karahan N., Göncü Serhatlığlu S. (2019). Gebelik Fizyolojisi. İçinde: Arslan Özkan H. Kadın Sağlığı ve Hastalıkları. Akademisyen Kitabevi. ss.135-170.

24. Alpay Türk V. (2015). Maternal Fizyoloji. Yıldırım G. İçinde Williams Obstetrik. Nobel Tip Kitabevleri. ss: 46-77.

25. Whiteley I, Gullick J. (2018). The Embodied Experience of Pregnancy with an Ileostomy. Journal of Clinical Nursing, 27,39313944.

26. Hundson CN. (1972). Ileostomy in Pregnancy, Journal of the Royal Society of Medicine, 65,281-283.

27. Pliego Pérez AR, García Pérez JD ve Neri-Ruz ES. (2001). Stomas in pregnancy, clinical case and review of the literatüre. Ginecologiay Obstetricia de Mexico. 69,449-452.

28. Gopal KA, Amshel AL, Shonberg IL, Levinson BA, VanWert M,VanWert J. (1985). Ostomy and Pregnancy. Dis Colon Rectum, 28, 912-916.

29. Bookstaver PN, Bland CM, Griffin B, Stover KR, Eiland LS, McLaughlin M. (2015). A Review of Antibiotic Use in Pregnancy, The Journal of Human Pharmacology and Drug Therapy, 35, (11), 1052-1062.

30. Miral M, Beji NK. (2017). Gebelikte İlaç Kullanımı ve Danışmanlık, Journal of Health Science and Profession, 4 (2), 142148 .

31. Akgün EZ, Yoldaş T. (2012). Intestinal Stoma, Kolon Rektum Hast Derg, 22,133-146.

32. Salvadalena G, Hendren S, McKenna L, Muldoon R, Netsch D, Paquette I, Pittman J, Ramundo J, Steinberg G, Dryden, B. (2015). WOCN Society and AUA Position Statement on Preoperative Stoma Site Marking for Patients Undergoing Urostomy Surgery. Journal of Wound, Ostomy and Continence Nursing, 42 (3), 253 256.

33. Aksoy G. (2019). Cerrahi Hemşireliği I, Ameliyat Öncesi Hemşirelik Bakımı, Edt. Aksoy G, Kanan N, Akyolcu N, Nobel Tıp Kitabevi, ss: 278-290.

34. Krouse RS, Grant M, Rawl SM, et al. (2009). Coping and Acceptance: The Greatest Challenge for Veterans with Intestinal Stomas, Journal of Psychosomatic Research, 66, 227-233.

35. Vural F, Erol F. (2013). Stomalı Hastalarda Yaşam Kalitesi Nasıl Yükseltilir? Dokuz Eylül Üniversitesi Hemşirelik Yüksekokulu Elektronik Dergisi. 6 (1), 34-39 